\title{
Study on Decision Process and Strategy Choice Behavior under Multimode Choice
}

\author{
Huanmei Qin, Hongzhi Guan, and Hai Yan \\ Beijing Key Laboratory of Traffic Engineering, Beijing University of Technology, Beijing 100124, China \\ Correspondence should be addressed to Huanmei Qin; hmqin@bjut.edu.cn
}

Received 16 July 2014; Accepted 9 September 2014

Academic Editor: Wuhong Wang

Copyright (C) 2015 Huanmei Qin et al. This is an open access article distributed under the Creative Commons Attribution License, which permits unrestricted use, distribution, and reproduction in any medium, provided the original work is properly cited.

Information Display Board is used to design an experimental survey and dynamic decision process data are retrieved under a multimode choice scenario with car, bus and subway, and park and ride. It is concluded that car travelers who will switch to choosing park and ride need more decision time to compare it with the existing modes (car, bus and subway) and tend to mainly use compensatory decision strategies in the decision process. The most commonly used decision strategy for travelers is the combined strategy under the multimode choice scenario. Correlation analysis shows that the influencing factors of age, whether the travelers have ever used park and ride, and decision time highly correlate with decision strategy choice. These conclusions have a certain reference value for theory research of decision process under multimode choice.

\section{Introduction}

With the increasing traffic congestion in many big cities, governments have given more priority to the development of public transport system. As a car and public transit united travel mode, park and ride can attract more private car travelers to transfer to using public transit such as railway and bus rapid transit into the city center area, thus alleviating traffic congestion in the city center area. Park and ride facilities have been built in many big cities all over the world and achieved very good results. Scholars have done much research on multimode choice. The central focus is to study how to encourage more people to use public transit through factor analysis and policy making.

Using analysis method of decision process, this paper will conduct a deep study of multimode choice process. These include the comprehensive consideration and tradeoff of various factors in the decision process, measurement index of decision strategies and decision strategy choice for different travelers. These analyses will help to grasp the decision mechanism under multimode choice and to provide the basis for the formulation of traffic demand management policy.

\section{Literature Review}

Decision is a process to choose one from two or more than two alternatives [1].

In many studies of multimode choice behavior, the most widely used research method is random utility theory. Many researchers such as Hole [2], Shirgaokar and Deakin [3], and Eric and Ilona [4] have conducted a preference survey for multimode choice including park and ride and established disaggregate modes choice models to analyze the travel choice behavior. The random utility theory is an economic method. It is regarded as a black box model which cannot explain the psychological decision process and the effect of decision strategy choice on decision behavior. Therefore, it is necessary to use the analytic methods of decision process and decision strategy choice to study the multimode choice behavior.

Currently, the related research on decision process and decision strategy choice is as follows.

Weber and Johnson have reviewed the decision research in the past 50 years. The research conclusion indicates that different decision results may have the same psychological decision process. The process model can give a definitive explanation for these decision phenomena [5]. 
Eliahu has studied drivers' reactions to congestion under time pressure using DFT (Decision Field Theory). Decision rules of lane switching on a congested road are tested at different levels of time pressure. The results show that people driving under congestion have an increasing use of noncompensatory decision strategy. The exogenous time pressure has effects on both the deliberation process and the use of information [6].

Bettman et al. have studied constructive consumer choice processes. Their research results indicate that consumer choice is inherently constructive. Due to limited processing capacity, consumers often do not have well-defined existing preferences but construct them using a variety of strategies contingent on task demands [7].

Chu and Spires have researched on perceptions of accuracy and effort of decision strategies. Their research results indicate that participants as a group understood the accuracy and effort dimensions of decision strategies. There was substantial variation across individuals in perceptions of various decision strategies [8].

Hey and Knoll have studied strategies in dynamic decision making. An experimental design is used to infer the decision strategy that people are using. A number of distinct decision heuristics were identified. These decision heuristics can be embodied into the economic models of dynamic decision process [9].

Elrod et al. have described and tested a model that captures conjunctive, disjunctive, and compensatory judgment and choice strategies, as well as selected hybrid combinations of these. The proposed model can be estimated solely from nonexperimental outcome data. The model is truly noncompensatory and allows decision makers to use different strategies across attributes. It provides a more plausible account of behavior than competing models [10].

Riedl et al. have presented a classification method that can detect different important decision strategies that people use in nonrisky multiattribute decision tasks. The classification method incorporates a multimethod approach that combines elements of both structural modeling and process tracing. For nine common characteristics of decision strategies, six of them can be used to develop one outcome-based and three process-based metrics in conjunction with a measure for direction of search [11].

Christopher has proposed a multiple-step transition method to analyze the more complex, longer transitions in decision process. It can provide a multivariate profile of the strategy. Empirical results show that the advantages of a multiple-step transition analysis are over single-step transition indices [12].

In summary, this paper will analyze decision process and decision strategy choice under a multimodes decision scenario with park and ride, car, and bus and subway using a decision process experimental survey.

\section{Decision Process Survey for Multimode Choice}

3.1. Survey Method. Travel mode choice is a decision process that individual continues processingof information. Strate- gies are used and reflected in the decision process. Due to the complexity of the decision process and the constraints of experimental means, accurate records of the psychology decision process for travelers are more difficult. Phenomena in information processing are the main research object in decision process analysis. The most direct, effective way is process tracing approach which is based on cognitive processing theory [13]. It uses a variety of process tracing technologies to analyze decision activities and understand the effect of various psychological factors on the decision process. There are three main types of process tracing technology including Protocol Analysis technology, Eye Movement Tracing technology, and Information Display Board (IDB) technology [14].

Protocol Analysis required participants to report all their thoughts in the decision process. These reported contents can be used to analyze the decision psychological process by encoding and processing. The actual operation difficulty and analysis work of this method are very large. It is also difficult to guarantee the reliability and validity.

Eye movement tracing is based on eye movement recording, fixation time, and the number of fixation, saccade distance, and pupil size data. These process data can be used to further analyze the intrinsic cognitive psychology process. This method can guarantee the truth of decision process and the scientificity of the data analysis. However, the eye tracker is expensive and complicated to operate.

Information Display Board (IDB) is the latest process tracking technology. It is simple and intuitive and can make a detailed record of the inner psychological activities in the decision process. Therefore, Information Display Board (IDB) technology is chosen to design the decision process survey in this paper. It is presented by an $m \times n$ information matrix. $m$ denotes the number of alternatives and $n$ denotes the number of attributes of alternatives. Each cell of the matrix represents the corresponding attribute values.

The Information Display Board (IDB) technology is improved and implemented in a custom electronic questionnaire using program software. Participants can make a final mode choice through the search and comparison of various alternatives and attributes. The recorded data can be used to analyze decision process and decision strategy choice behavior.

3.2. Survey Design. The survey content includes some aspects as follows.

3.2.1. Personal Information and Daily Travel Information. The personal information includes gender, age, and income.

Daily travel information includes whether the participant has ever used park and ride facilities.

3.2.2. Decision Scenario Design. Given a multimode choice decision scenario, the travel is assumed from home (Penglai apartment in Changping district) to work place (Xidan book center in Xicheng district) in Beijing. A screenshot of Beijing electronic map marked with the above home, work place, and park and ride facility is presented to the participants. The 


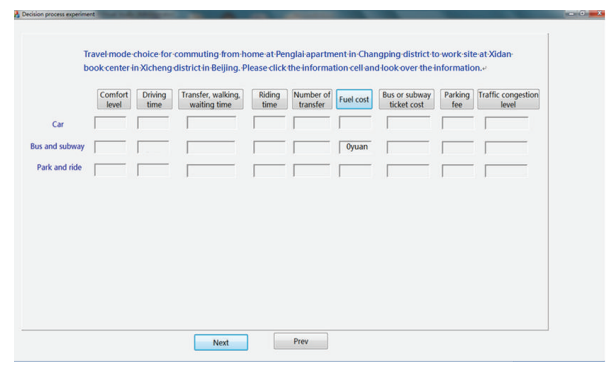

FIgure 1: Decision scenario design.

optional travel modes are assumed to be three: car, bus and subway, and park and ride. Participants will search, compare, and analyze the information of different travel modes and then make a travel mode choice. The influencing factors, as shown in Table 1, include comfort level, driving time, riding time, transfer, walking and waiting time, number of transfers, fuel cost, bus or subway ticket cost, parking fee, and traffic congestion level. These influencing factors and their values are given according to the survey data for park and ride users in Beijing, China, in June 2010 [15].

3.2.3. Survey Procedure. As shown in Figure 1, the information for each cell of the matrix is invisible at first. Then, the participant needs to click the information cell of influencing factors one after another to reveal the corresponding information. When the participant clicks next information cell, the information in the previous cell will hide.

There is no time limit for the information search, contrast and analysis process until the participant can make the final mode choice according to the viewed information. At this time, the participant can click on the "next" button in the bottom and choose a travel mode [16].

In order to make the participants familiar with the information search interface and operation process, a simple example of mobile phones choice is given as a practice before the formal experiment.

The interface has the necessary explanations and descriptions and participants can use the computer mouse to complete the whole experiment.

The experimental data is automatically recorded into a specified Excel file in the experimental process. It includes the mode choice result, decision time, and the viewed sequence for information cells.

3.3. Survey Implementation. The survey object is people who own at least one car and used to drive a car.

The survey is carried out in 2012. The electronic software package is sent to the participants. They use their own computer to complete the experiment content and return the result file at the appointed time.

The retrieved sample is 124 and the effective sample is 107.

According to the experimental data, $68 \%$ of the participants are men and $90 \%$ of them are between 21 and 40 years old. $83 \%$ of the participants have monthly income between
2000 and 10000 yuan. $13 \%$ of participants have ever used the park and ride facility.

\section{Analysis of Decision Strategy Choice Behavior}

Decision strategies are used in the decision process when individuals extract attribute information and prior knowledge to make a choice in the decision task.

4.1. Types of Decision Strategies. Decision strategies for multiattribute and multimode decision task are generally divided into two categories: compensatory strategy and noncompensatory strategy.

Compensatory strategy is that decision makers investigate all the attributes of each option in the information search process. For different attributes of the same option, a deficiency of one attribute can be compensated by the advantages of the other attributes. The final decision will be made after a comprehensive comparison of all options. The basic assumption is that the attributes of options are independent of each other and mutual compensation between different attributes. Compensatory strategies include linear model and cumulative difference model.

Noncompensatory strategy is that decision makers will not investigate all the attributes of each option in the decision process. For different attributes of the same option, a deficiency of one attribute can not be compensated by the advantages of other attributes. Decision makers used to make a subjective assessment for the importance of each attribute or develop minimum acceptance criteria for each attribute. Then they compare and eliminate options on the basis of these main principles. Noncompensatory strategies include satisfaction strategy, elimination by aspects, lexicographic strategy, and majority of confirming dimensions strategy.

In addition, in the face of complex decision making tasks, individuals may use two or more kinds of strategies, namely, the combined strategy.

4.2. Measurement Indices of Decision Strategies. Decision strategies used in the decision process can be identified through the following indices.

4.2.1. Decision Time. Decision time refers to the total time of psychological decision process spent in a travel mode choice and is measured in seconds. The decision process includes from searching information to making a final choice. The longer the decision time, the more complex the decision process.

Figure 2 shows the decision time distribution. Participants whose decision time is between $10 \mathrm{~s}$ and $20 \mathrm{~s}$ have the highest proportion, accounting for $25 \%$. The next is between $30 \mathrm{~s}$ and $40 \mathrm{~s}$ and between $40 \mathrm{~s}$ and $50 \mathrm{~s}$ and the proportion is $16 \%$, respectively. Altogether, there are $72 \%$ of the participants whose decision time is between $10 \mathrm{~s}$ and $50 \mathrm{~s}$. There is also a part of the participants whose decision time is relatively long. The proportion of participants whose decision time is above 


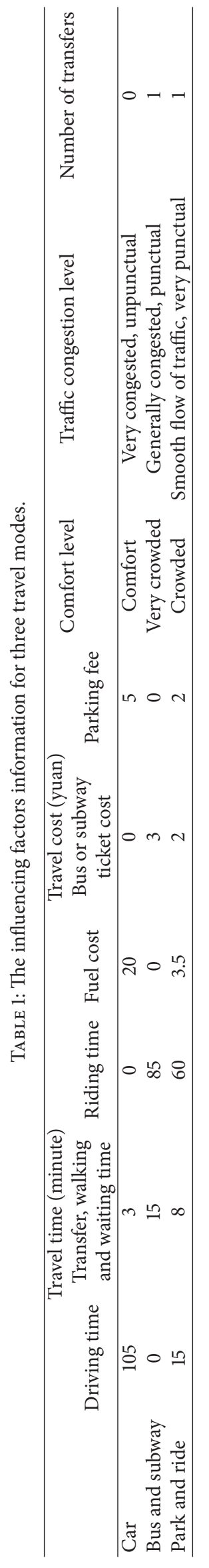




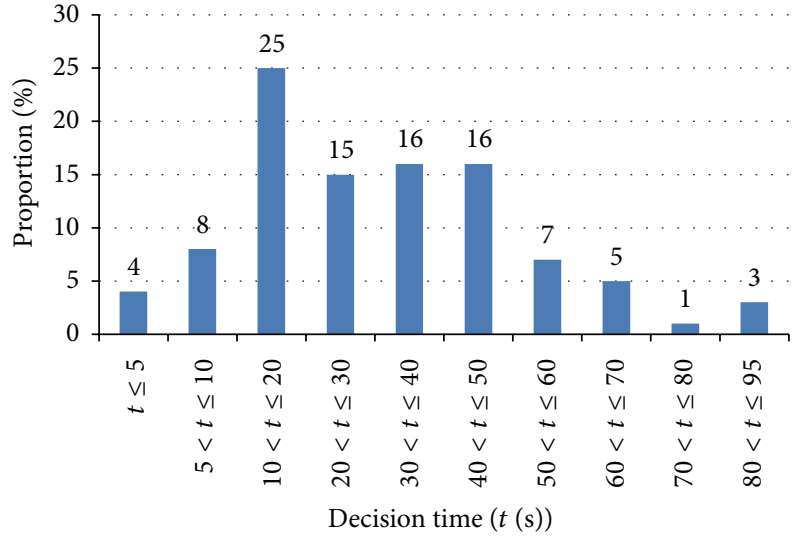

FIGURE 2: Decision time distribution.

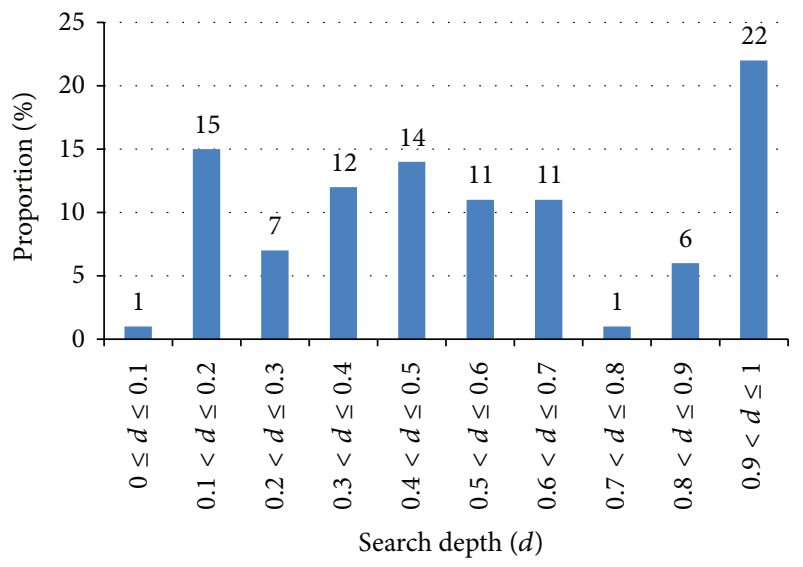

FIGURE 3: Distribution of information search depth.

$60 \mathrm{~s}$ is $9 \%$. This indicates that some travelers' decision process is complex.

4.2.2. Information Search Depth. Information search depth refers to the ratio of the information cells searched to the total attribute information cells. Its computation does not consider the number of times that the information cell has been repeatedly opened and viewed. The range of information search depth is between 0 and 1 . High information search depth indicates that the participants have analyzed, compared, and weighed information many times in the decision process and compensatory decision strategies are often used. Conversely, when the information search depth is low, the participants are more likely to use noncompensatory decision strategies.

The distribution of information search depth is shown in Figure 3. It can be seen that the highest proportion of information search depth is between 0.9 and 1 . This indicates that $22 \%$ of participants search for almost all information cells and make a decision process including analyzing, comparing, and weighing information before the final mode choice reached. The information search depth which is between 0.1 and 0.2 and between 0.4 and 0.5 has a higher proportion, accounting for $15 \%, 14 \%$, respectively. Overall, there are

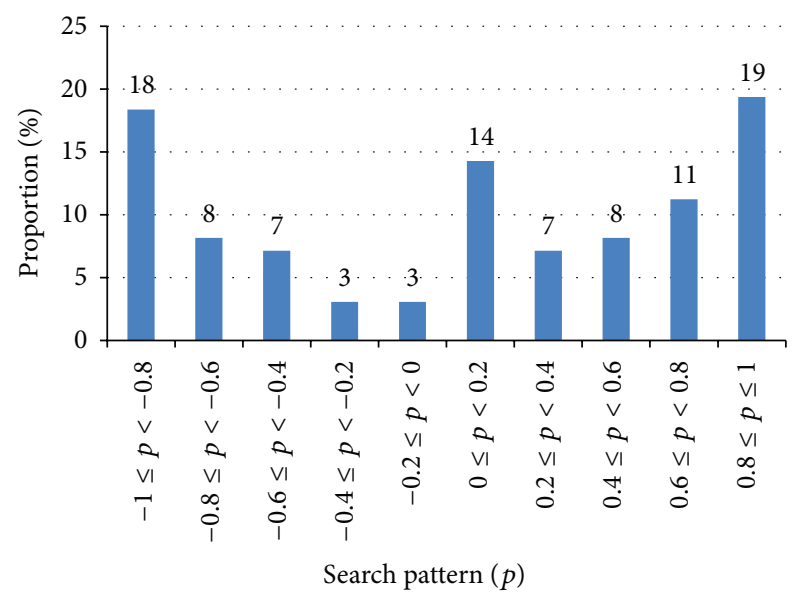

FIGURE 4: Distribution of information search pattern.

$70 \%$ of the participants whose information search depth is between 0.2 and 0.7 .

4.2.3. Search Pattern for Information. The search pattern for conversion between different options is that the participants search all the attributes of one option and then search all the attributes of the other option in the decision process. The search pattern for conversion between different attributes is that the participants search all the options on the same attribute and then search for another attribute of all the options. Search pattern $=$ (the times of move between options - the times of move between attributes)/(the times of move between options + the times of move between attributes). The range of search pattern is between -1 and 1 . Positive search pattern value indicates that information process is mainly based on options. Negative search pattern value indicates that the information process is mainly based on attributes. The search pattern based on options will be dominant with the increasing of the search pattern value [17]. Option based information search pattern is widely regarded as one in which the compensatory decision strategy will be used.

As shown in Figure 4, there are 39\% of participants whose search pattern value is between -1 and 0 . There are $18 \%$ of participants whose search pattern value is between -1 and -0.8 . This indicates that they mainly used the search pattern based on attributes. There are $61 \%$ of participants whose search pattern value is between 0 and 1 . There are $19 \%$ of participants whose search pattern value is between 0.8 and 1 . This indicates that they mainly used the search pattern based on options.

There are $14 \%$ of participants whose search pattern value is between 0 and 0.2 in the middle position. This search pattern can be considered to be a mixed one including both compensatory and noncompensatory strategies used in the decision process.

4.2.4. Variability of the Information Search. Variability of information search refers to the standard deviation of information search amount for different options. When the information search amount for each option is the same, the 


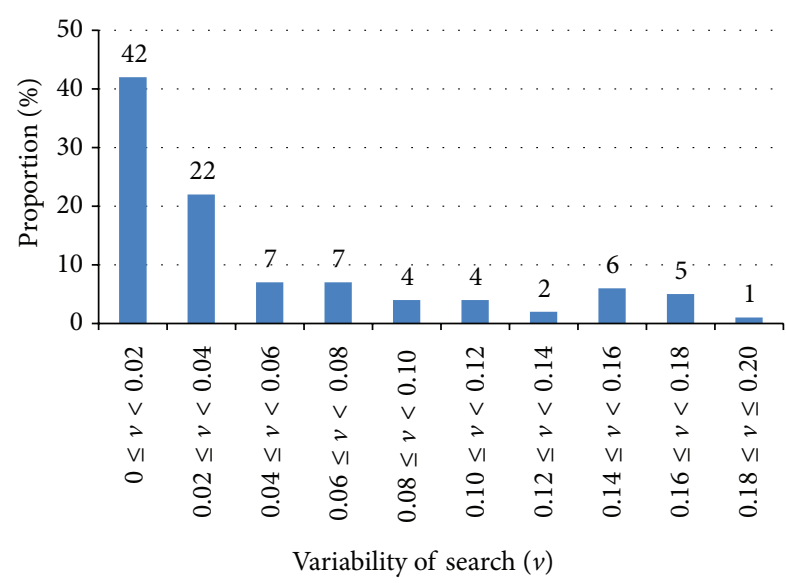

FIGURE 5: Distribution of variability of information search.

variability value of the information search is zero. The higher the variability value, the more the noncompensatory strategy will be used.

As can be seen from Figure 5, there are $42 \%$ of participants whose variability of information search is between 0 and 0.02 and $22 \%$ of them are between 0.02 and 0.04 . These indicate that there is little difference among each option in the information search quantity for most participants.

As shown in Table 2, for decision time, the participants who choose park and ride cost more decision time and those who chose bus and subway cost less decision time. This means that car travelers who will transfer to choosing park and ride are more likely to take longer time to search for and process information and make decisions.

The mean of the information search depth shows that there is small difference for participants who choose different travel mode in the decision process.

For the information search pattern, the participants who choose park and ride tend to mainly use the decision strategy based on options and those who choose bus and subway tend to mainly use the decision strategy based on attributes.

The participants who choose park and ride have the maximum variability of information search and its value is 0.0521 .

In general, if park and ride facility is provided as a new united travel mode, car travelers who will transfer to choosing park and ride need more decision time to compare it with the existing travel modes (car, bus and subway) and mainly use compensatory decision strategies based on options.

4.3. Analysis of Decision Strategy Choice. Information search pattern and variability of information search are usually used to determine different decision strategies in decision process [18]. (1) When the search pattern is based on options, the variability value is equal to 0 , representing the linear additive strategy, while the variability value is greater than 0 , representing the combined strategy; (2) when the search pattern is based on attributes, the variability value is equal to 0 , representing the cumulative difference strategy, while

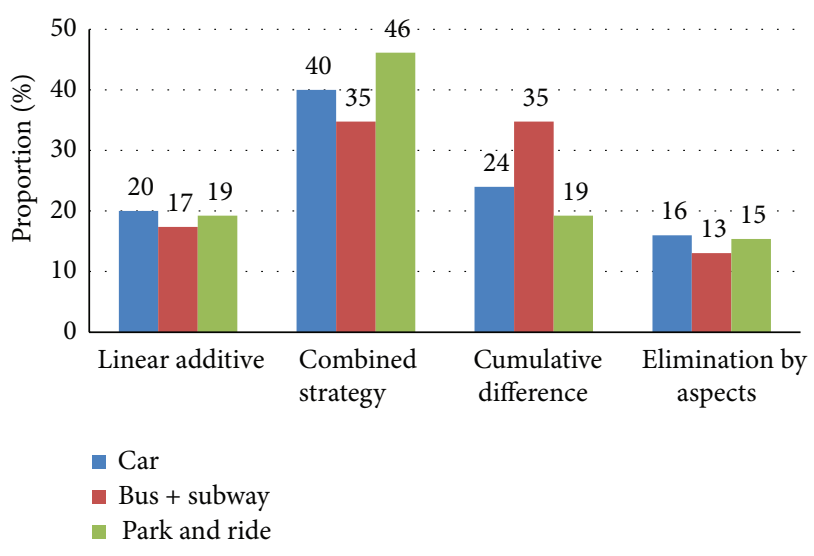

FIGURE 6: Distribution of decision strategy choice.

the variability value is greater than 0 , representing the elimination by aspects strategy.

As can be seen from Figure 6, the choice proportion for combined strategy is the most, followed by the cumulative difference strategy and linear additive strategy. The choice proportion of elimination by aspects strategy is the least. Combined strategy is mainly used for participants who choose park and ride, and the choice proportion is $46 \%$. The participants who choose bus and subway mainly use combined strategy and cumulative difference strategy and the choice proportion is $35 \%, 35 \%$, respectively.

Gender, age, income, and whether the participant has ever used park and ride are chosen as important influencing factors to make a correlation analysis with decision strategy choice. The decision strategies of the linear additive strategy, combined strategy, cumulative difference strategy, and elimination by aspects strategy are assigned to 1, 2, 3, 4 .

As shown in Table 3, the influencing factors of age, whether the participants have ever used the park and ride, and decision time highly correlate with decision strategy choice. Age has a significant negative correlation with decision strategies choice. This indicates that the older are more likely to use search pattern based on options and compensatory decision strategies. The factor that whether the participants have ever used park and ride and decision strategy choice is negatively correlated. This indicates that participants who have ever used park and ride are more likely to use search pattern based on attributes and noncompensatory decision strategies. Decision time has a negative correlation with decision strategy choice. The longer the decision time is, the more the participants tend to use search pattern based on options and compensatory decision strategies. In addition, decision time has a positive correlation with decision depth. The longer the decision time, the more the amount of information searched.

\section{Conclusions}

In this paper, Information Display Board is used to design a multimode experimental survey and dynamic decision process data are retrieved under a multimode choice scenario 
TABLE 2: Summary for the mean of decision process indices.

\begin{tabular}{lcccc}
\hline Mode & Decision time (s) & Search depth & Search pattern & Variability of search \\
\hline Car & 32.091 & 0.5822 & 0.0640 & 0.0294 \\
Bus and subway & 23.147 & 0.5539 & -0.1024 & 0.0429 \\
Park and ride & 34.458 & 0.5434 & 0.1066 & 0.0521 \\
\hline
\end{tabular}

TABLE 3: The relation between influencing factors and decision strategy choice.

\begin{tabular}{|c|c|c|c|c|}
\hline Factors & Relation index & Decision time & Decision depth & Decision strategy \\
\hline \multirow{2}{*}{ Gender (male 1, female 2) } & Pearson correlation & 0.066 & 0.060 & 0.075 \\
\hline & Sig. (2-tailed) & 0.528 & 0.563 & 0.473 \\
\hline \multirow{2}{*}{ Age } & Pearson correlation & 0.202 & 0.164 & $-0.286^{* *}$ \\
\hline & Sig. (2-tailed) & 0.050 & 0.115 & 0.005 \\
\hline \multirow{2}{*}{ Income } & Pearson correlation & 0.059 & -0.017 & -0.080 \\
\hline & Sig. (2-tailed) & 0.572 & 0.870 & 0.445 \\
\hline \multirow{2}{*}{ Ever used park and ride (yes, 1, no, 2) } & Pearson correlation & 0.186 & 0.124 & $-0.210^{*}$ \\
\hline & Sig. (2-tailed) & 0.073 & 0.235 & 0.042 \\
\hline \multirow{2}{*}{ Decision time } & Pearson correlation & 1 & $0.512^{* *}$ & $-0.234^{*}$ \\
\hline & Sig. (2-tailed) & & 0.000 & 0.023 \\
\hline \multirow{2}{*}{ Decision depth } & Pearson correlation & & 1 & -0.171 \\
\hline & Sig. (2-tailed) & & & 0.100 \\
\hline
\end{tabular}

${ }^{*}$ Correlation is significant at the 0.05 level (2-tailed).

${ }^{* *}$ Correlation is significant at the 0.01 level (2-tailed).

with car, bus and subway, and park and ride. Some conclusions can be drawn from the above analysis.

Under the existing travel modes (car, bus and subway), car travelers who will transfer to choosing park and ride need more decision time to compare it with the existing modes and mainly use compensatory decision strategies based on options.

Among the decision strategies, combined strategy is the most commonly used, followed by the cumulative difference strategy and linear additive strategy.

Correlation analysis shows that the influencing factors of age, whether the participants have ever used the park and ride, and decision time highly correlate with decision strategy choice.

These conclusions have a certain reference value for theory research of decision process under multimode choice.

\section{Conflict of Interests}

The authors declare that there is no conflict of interests regarding the publication of this paper.

\section{Acknowledgments}

This research was supported by National Natural Science Foundation (51308016) and National Basic Research Program of China (no. 2012CB725403). The authors are very grateful for the comments from the anonymous reviewers.

\section{References}

[1] R. P. Stephen, Organizational Behavior, Renmin UP, Beijing, China, 1997, Translated by J. M. Sun.

[2] A. R. Hole, "Forecasting the demand for an employee Park and Ride service using commuters' stated choices," Transport Policy, vol. 11, no. 4, pp. 355-362, 2004.

[3] M. Shirgaokar and E. Deakin, "Study of park-and-ride facilities and their use in the San Francisco Bay Area of California," Transportation Research Record, no. 1927, pp. 46-54, 2005.

[4] M. Eric and B. Ilona, "Exploring heterogeneity in park and ride preferences: a latent class mode," in Proceedings of the TRB Annual Meeting, 2009, CD-ROM.

[5] E. U. Weber and E. J. Johnson, "Mindful judgment and decision making," Annual Review of Psychology, vol. 60, pp. 53-85, 2009.

[6] S. Eliahu, "Reactions to congestion under time pressure," Transportation Research Part C: Emerging Technologies, vol. 7, no. 2-3, pp. 75-90, 1999.

[7] J. R. Bettman, M. F. Luce, and J. W. Payne, "Constructive consumer choice processes," Journal of Consumer Research, vol. 25, no. 3, pp. 187-217, 1998.

[8] P. C. Chu and E. E. Spires, "Perceptions of accuracy and effort of decision strategies," Organizational Behavior and Human Decision Processes, vol. 91, no. 2, pp. 203-214, 2003.

[9] J. D. Hey and J. A. Knoll, "Strategies in dynamic decision making-an experimental investigation of the rationality of decision behaviour," Journal of Economic Psychology, vol. 32, no. 3, pp. 399-409, 2011.

[10] T. Elrod, R. D. Johnson, and J. White, "A new integrated model of noncompensatory and compensatory decision strategies," Organizational Behavior and Human Decision Processes, vol. 95, no. 1, pp. 1-19, 2004. 
[11] R. Riedl, E. Brandstätter, and F. Roithmayr, "Identifying decision strategies: a process-and outcome-based classification method," Behavior Research Methods, vol. 40, no. 3, pp. 795-807, 2008.

[12] C. Ball, "A comparison of single-step and multiple-step transition analyses of multiattribute decision strategies," Organizational Behavior and Human Decision Processes, vol. 69, no. 3, pp. 195-204, 1997.

[13] M. Schulte-Mecklenbeck, A. Kühberger, and R. Ranyard, A Handbook of Process Tracing Methods for Decision Research: A Critical Review and User's Guide, Psychology Press, New York, NY, USA, 2011.

[14] P. W. Glimcher, "Making choices: the neurophysiology of visualsaccadic decision making," Trends in Neurosciences, vol. 24, no. 11, pp. 654-659, 2001.

[15] H. M. Qin, H. Z. Guan, X. L. Ao, and Y. Liu, "Park and ride survey analysis," Urban Transport of China, vol. 10, no. 1, pp. 8083, 2012.

[16] H. Qin, H. Guan, and Y.-J. Wu, "Analysis of park-and-ride decision behavior based on Decision Field Theory," Transportation Research F, vol. 18, pp. 199-212, 2013.

[17] J. W. Payne, J. R. Bettman, and E. J. Johnson, "Adaptive strategy selection in decision making," Journal of Experimental Psychology: Learning, Memory, and Cognition, vol. 14, no. 3, pp. 534-552, 1988.

[18] A. G. Abdul-Muhmin, "Contingent decision behavior: effect of number of alternatives to be selected on consumers' decision processes," Journal of Consumer Psychology, vol. 8, no. 1, pp. 91111, 1999. 


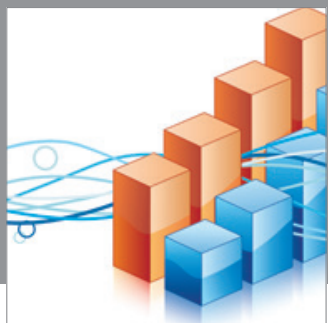

Advances in

Operations Research

mansans

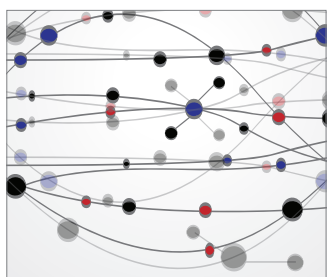

The Scientific World Journal
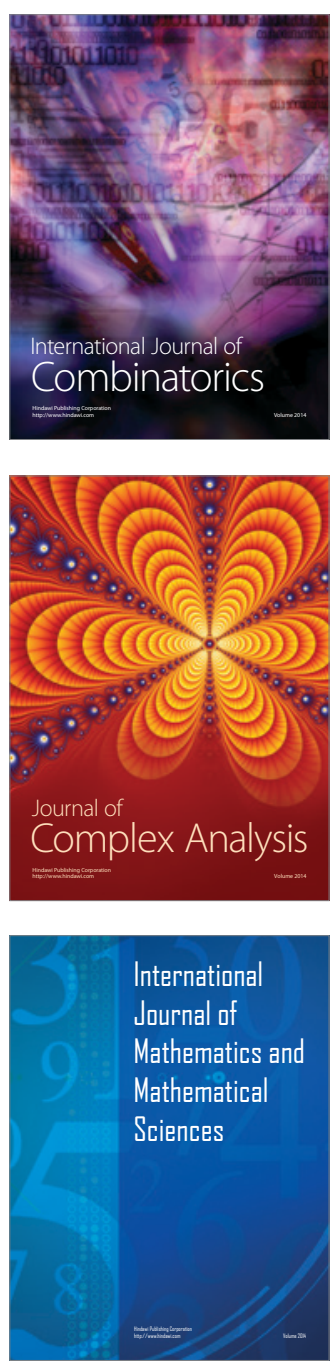
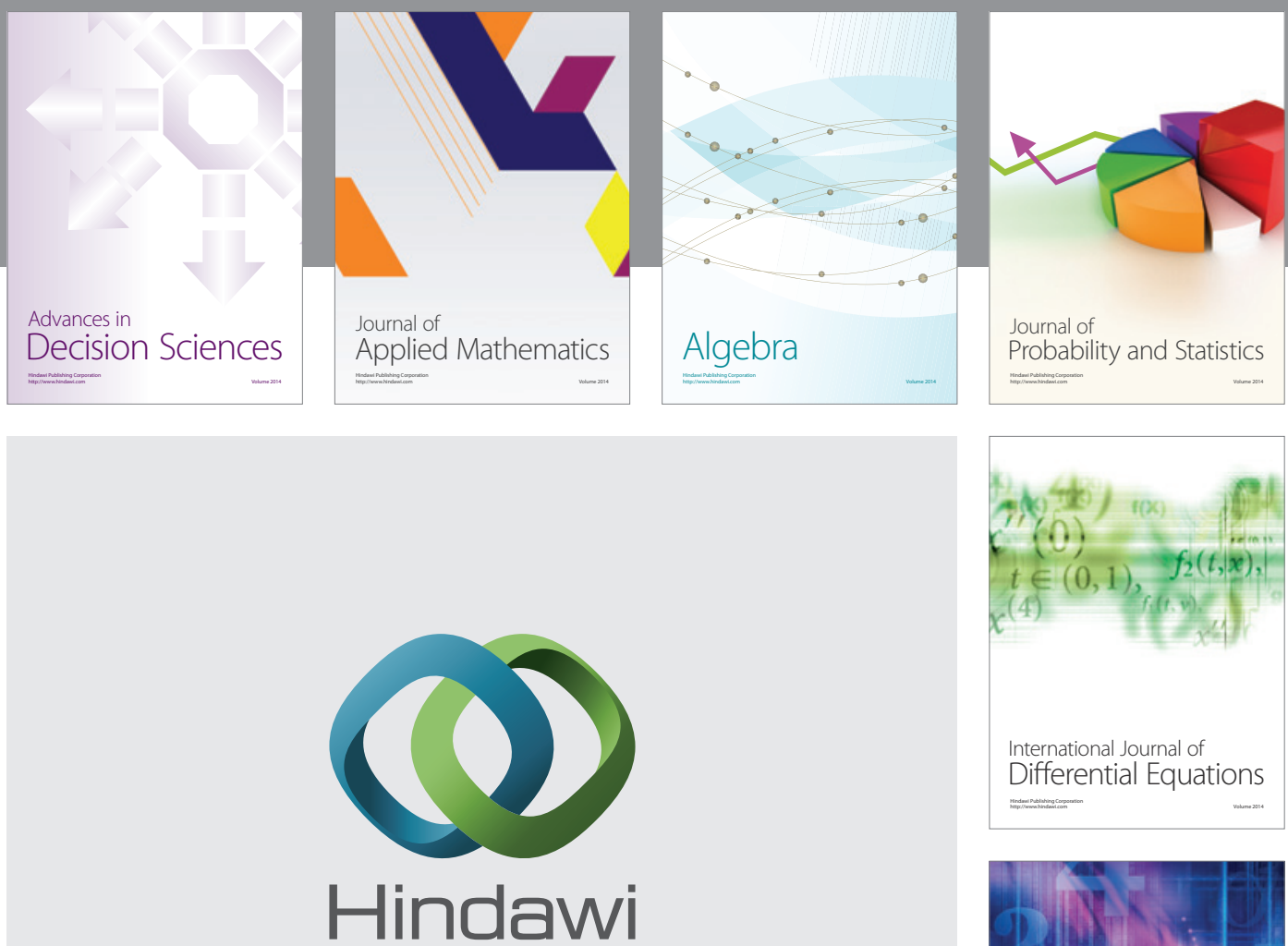

Submit your manuscripts at http://www.hindawi.com
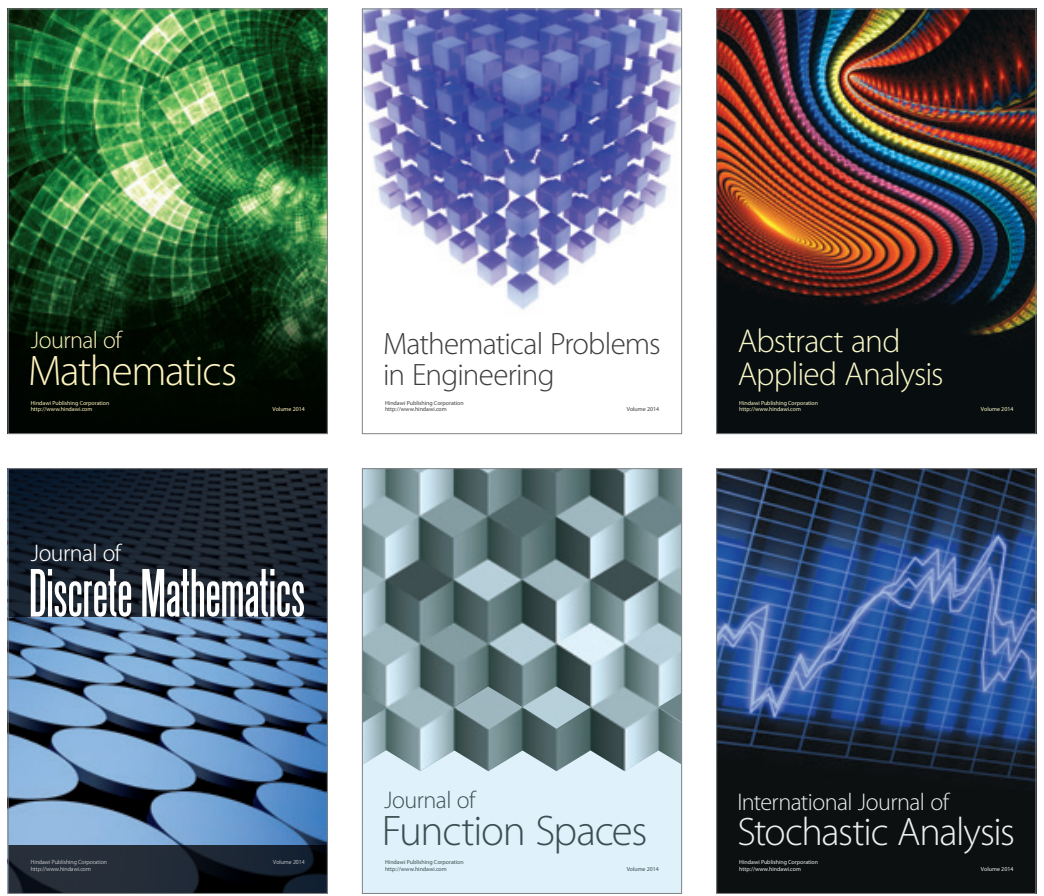

Journal of

Function Spaces

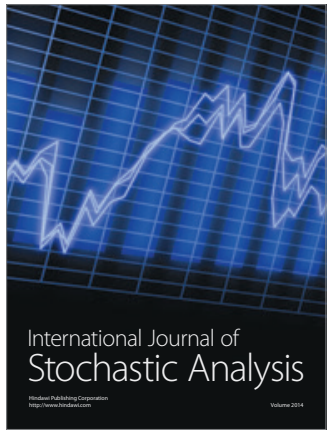

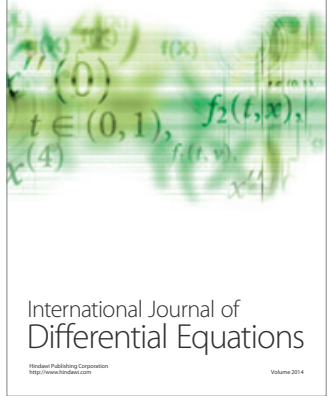
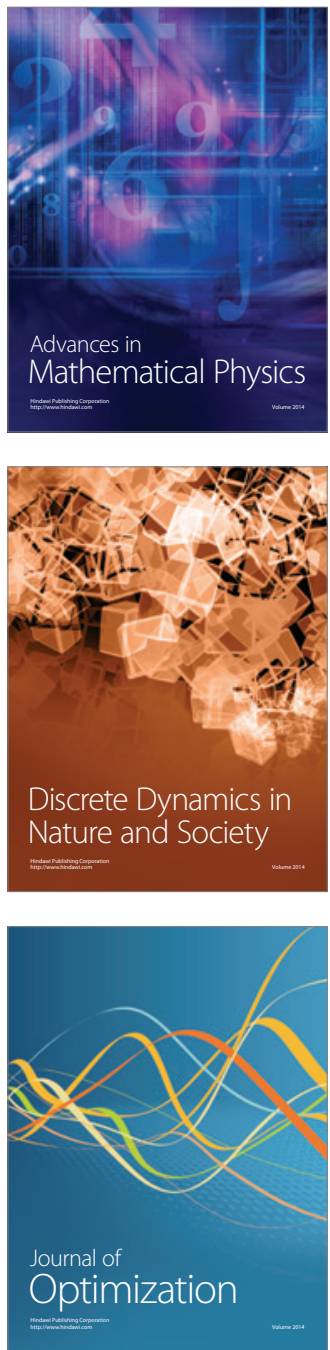